\title{
DR. HARRINGTON TUKE'S EVIDENCE BEFORE THE DILLWYN COMMITTEE.
}

The following correspondence has taken place in reference to the article on Lunacy Law in our January number:-

$$
\begin{aligned}
& \text { 24, Essex Street, Strand, } \\
& \text { London, W.C., } \\
& \text { 23rd January, } 1878 .
\end{aligned}
$$

Gratinexn, -Dr. Tuke has had his attention drawn to the last number of the "Journal of Mental Science." He is far from wishing to curb public criticism of his views, sentiments, and acts, provided it is done honestly, but he does not consider your allusions to him in folio $\mathbf{4 8 5}$ of the number alluded to are either true or fair, containing, as they do, statements which are calou. lated to create a most unjust prejudice against himself and his establishment. With regard to your critioism of what you allude to as a "grave charge," a reference to the reports will show that the circumstances you refer to are quoted in a different report-viz., in 1877-to that quoted by Dr. Tuke, and hence the test of Dr. Take's candour and accuracy is unjust and anfounded.

With regard to your allusion to an unfortunate suicide at Dr. Tuke's estab. lishment, as establishing a " record of mismanagement greater than anything to be found in the Commissioners' entries regarding the Hospitals," this Dr. Tuke considers as an unfair aspersion upon himself and his establishment.

As you have all the materials before you for ascertaining the inaccurate statements to which we have allnded, we must ask you to publish such a retractation of the serions comments you have thought proper to make as will set Dr. Tuke's conduct and management right in the eyes of those whose good opinion he most prizes.

$$
\text { We are, Gentlemen, }
$$

Your obedient Servants,

To the Editors of the

GEO. H. K. \& G. M. FISHER.

$$
\begin{gathered}
\text { "Journal of Mental Bcience," } \\
\text { 9, Hanover Square. }
\end{gathered}
$$

Royal Edinburgh Aeylum for the Insane, Edinbargh, February 6th, 1878.

Gentrinurx, - In reply to your letter of 23rd January last, we beg leave to repudiate emphatically the charge made by you on behalf of Dr. Harrington Tuke that the criticiam in the January number of the Journal in regard to that gentleman's published ntterances was not done "honestly," or was other than "true" or "fair." At the same time, if we have unintentionally admitted any errors as to matters of fact into the article of which Dr. Harrington Tuke complaing, we shall be happy to publish a correction in our $\Delta$ pril number on being informed what they are.

The grave charge which Dr. Tuke made against the whole of the Registered Hospitals consists of two connts-First, he says sweepingly, withont making even a single exception, that "The last report of the Commissioners contains records of mismanagement and complaints against these Hospitals." That is the grave and damaging charge Dr. Tuke thought it right to make against Hospitals that are public institutions in great part of a charitable nature, not conducted with a view to profit but with sole reference to the welfare of their unfortunate inmates, and which are justly considered the greatest boons to the insane in this country.

The last report of the Commissionerg-that for 1876-was referred to in the article to show that Dr. Tuke's statement wes unfair to these Hospitale. 
You inform us in your letter that Dr. Tuke was quoting a different report, without, however, stating which report that was. If it be the report for 1875 -and the writer of the article assures us that such a supposition never occurred to his mind until the receipt of your letter-we still anhere to the opinion that Dr. Tuke's grave charge was not sapported by facts. In that very report the Commissioners in Lunacy expressly state-" Generally speaking, the reports will be found farourable to the management of the Registered Hospitals during the past year."

In the report for 1874 they say again that " the general condition of these institutions is quite satisfactory."

In the report for 1873, again, they say-" The Hospitals continue, in general, as our entries will show, to deserve favourable notice."

The discrepancy as to which was "the last report" is the only ground yon have for saying that " the test of Dr. Tuke's candour and accuracy is nnjust and unfounded." You do not venture to deny that Dr. Tuke's statements, tested by the report of 1876, are fairly criticised, and the foregoing extracts will show you how they would stand if tested by previons reports.

In order, however, that there may be literal accuracy in this matter, we shall, on your informing us definitely to which report Dr. Tnke intended to refer, be willing to explain in our next number that the writer of the article had mistaken the report which Dr. Tuke had in mind; that he regrets such a mistake should have occurred ; and then test the accuracy and justice of that gentleman's observations by the report referred to.

The "Journal of Mental Science" would fail in its duty to the members of the Medico-Psychological Association, and to the public, were it not to defend these great Hospitals, provided by the charity of the nation, from charges calculated to do them and their unfortunate inmates great harm in the eyes of the public, and seriously to disquiet the minds of those who have relations or friends in them.

The second count of Dr. Tuke's grave charge was, in our opinion, still more serious, and cannot be even mitigated by any possible misunderstanding as to the dates of reports. When Dr. Tuke thought proper to state about a large body of his professional brethren, whose repatation he must admit to be as im. portant to them as his own is to himself, that " not one" of them " has any repute for treatment," his words were calculated to do them a grave injury, and our Journal would have atterly failed in its duty had it not condemned a statement which is as a mazing as it is unjust. As to our remarks on this charge, we have not only no "retractation" to make, but we feel that our article was far from being as severe as a charge of such a nature warranted.

With regard to the passing reference to the pages of the Commissioners report, in which they give an account of a suicide in Dr. Tuke's establishment -namely, that which had occurred before his evidence was given (and we beg lerve particularly to direct your attention to the fact that the words in your letter within quotation marks are not taken from the pages of our Journal)we are anthorised by the writer of the article to state that nothing but a strong feeling that it was his duty to defend effectually institutions of great publio usefulness wonld have made him refer to this, and show that Dr. Tuke's own establishment was itself liable to the same unfortunate oocurrences as those which apparently he makes use of to throw discredit upon the Hospitals. If Dr. Tuke does not found a charge of " mismanagement" againgt the Hospitals on such occurrences, it is strange that he should now ask us for a "retractation" of the cursory allusion to a case which happened within his own establishment, and the account of which is contained in a publio report.

But as it is a matter of opinion, after all, whether any fact eatablishe "mismanagement" in an asylum, publio or private, we shall be most willing to print the whole of the facts in regard to the suicides, \&c., in the public Hospitals and in Manor House Private Asylum from the reports of the Commissioners in Lanacy in our next number, should Dr. Harrington Tuke wish it. 
We propose to print your letter and this reply in the April number of our Journal, a course to which, we presume, your client can bave no objection.

I am, Gentlemen,

Your obedient Servant,

T. B. CLOUSTON,

On behalf of the Editors of the

Messrs. Geo. H. K. \& G. M. Fisher.

\author{
"Journal of Mental Science."
}

\title{
24, Essex Street, Strand, \\ London, W.C. \\ March 19th, 1878.
}

GENTLEMEN, - We have received with surprise and regret your answer to our letter-regret that you do not at once send a suitable apology for the flagrant mistake you have obviously committed, surprise that you should still affect not to know which report it was Dr. Tuke quoted from. We will in a few words prove that you must know this perfectly well.

Dr. Tuke was called before the Select Committee on the 21st of April, 1877; the Senior Editor of the Journal, Dr. Maudsley, gave evidence on the 27th of the same month, and was subsequently recalled, at his own request. The evidence must be familiar to him, and he must know that in the review we cum. plain of the absurd error has been made of comparing Dr. Tuke's statements from the Blue Book of 1876 , in April. with the facts and figures of a Blue Book published in August, 1877-four months afterwards - and editorially reviewed in the Journal in 1878 !

The reviewer states, and your letter repeats, these words:- "Dr. Tuke says that 'the last report of the Commissioners in Lunacy contains records of mismanagement and complaints against the Registered Hospitals. That is the grave and damaging charge Dr. Tuke thought it right to make." The reviewer adds :- "This is indeed a grave charge; if not true, Dr. Tuke should not have made it. In simple justice to these gentlemen and their institutions, we must again turn to the report to which Dr. Tuke refers. We find nothing but praise of their ccndition and management; the only statement in the nature of complaints are-" Here follow some trivial matters which show that the reviewer is quoting the report published in August last, which has nothing to do with the evidence given in the preceding April.

You say, again, in your letter that you still udhere to your opinion that " $\mathrm{Dr}$. Tuke's grave charge was not supported ly facts," and you attempt to prove this by quoting from the report $\mathrm{Dr}$. Tuke and the Committee really had before them - in that very report the Commissioners in Lunacy expressly state that generally speaking the report will be found favourable to the management of the Registered Hospitals during the past year."

This would seem to decide the case against Dr. Tuke; but it seems almost incredible that gentlemen of your position should so unfairly try to damage our client's evidence. You have studiously omitted half of the sentence, thus giving " the principal exception," \&c., which is precisely the cuse referred to by Dr. Tuke in his statement to the Committee, and if it had been mentioned, would have again identified the report.

On turning to the 30th repurt, we find during 1875, in the Registered Hospitals, that the death by "violence" was consequent upon an attempt to put a patient into a straight waistcoat ; that a Registered Hospital physician has treated a patient with acute mania in a farm house, and is cautioned for doing Bo without certificates; that there are three cases of suicide; that a patient is reported to have died whose life might bave been saved had he been seen by any medical man, and this in " cnnsequence of the defective nature of the arrangements and management of the Hospitai." There are many cases of mechanical restraint and seclusion. As to the latter, a case is recorded by the Commissioners of a patient in a Registered Hospital who, left alone in a padded 
room, gorged out his eyes with his own fingers 1 It would seem that $\mathrm{Dr}$. Tuke avoided sensational and damaging statements, and made no charge whatever; he spoke with much forbearance as to one fact only; he mentioned no name. Dr. Tuke did not take advantage of an exceptionul year to try and damage professional men for whom he has high esteem. He desires us to say that he does not wish, as you offer, that the details of these distressing cases should be republished in the Journal. Whether you will publish the sad accident in his own institution is indifferent to him, but on this subject we have some serious renarks to make.

Your article insinuates that the suicide occurring at Chiswick arose from mismanagement on Dr. Tuke's part. You say it occupies a page and a half of the Blue Book; you do not say that the page and a half is taken up by the proceedings in regard to the attendant "whose wilful disobedience" of Dr. Tuke's orders led to the melencholy event. You must by this omission intend to injure Dr. Tuke and his asylum. The whole tenor of the article evinces the same desire. Thus you sneer at, and "put on record the fact that Dr. Tuke had ondered restraint in a particular case for three nights," as if it were his com. mon practice; while you knew that Dr. Tuke was a son-in-law, pupil, and executor of the late Dr. Conolly, and an ardent supporter of his views as to non-restraint. Again, you say, and significantly add, "Comment is unnecessary." That the cures at Manor House in 1876 were only 12 per cent. A reference we have made to the official records of that establishment show that during the thirty years of Dr. Tuke's management the cures have amounted to 40 per cent. per annum. This, again, must be to injure Dr. Tuke's practice. Your minor attack upon Dr. Tuke he leaves to the judgment of his professional brethren, who will, he trusts, consult the whole text of Dr. Tuke's evidence in the Blue Book, and not trust to your extracts.

We again ask for an apology, and are, Gentlemen,

$$
\text { Your obedient servants, }
$$

G. H. K. \& G. M. FISHER

Dr. Clouston,

$$
\text { (Duplicate sent to Dr. Maudsley.) }
$$

Royal Asylum for the Insane,

Edinburgh.

Tipperlinn House, Morningside, Edinburgh, 9th April, 1878.

GhNTLEmen,-As one of the Editors of the "Journal of Mental Science," I am in receipt of your letter of the 19th ult. In it you assume that because Dr. Maudsley gave evidence before the Select Committee of the House of Commons he must have been famliar with Dr. Harrington Tuke's evidence, and you conclude from that assumption that the mistake of the Blue Book of 1876 for the one of 1875 was not made in good faith. This makes it incumbent upon me to state-what my initials to the article sufficiently indicated - that it was -written by me; that it was not seen by Dr. Maudsley, who had nothing whatever to do with it, until it was in print in the paged proofs, and that I appended my initials in onder to assume responsibility for the opinions and recommendations in it, some of which are directly opposed to his opinions as given in evidence before the Select Committee.

With reference to Dr. Maudsley's supposed familiarity with Dr. Tuke's evidence, I have received the following letter:-

“ Drar Dr. CLnUSTon,-Messrs. Fisher are quite mistaken in supposing that I am familiar with Dr. Tuke's evidence. I was not present at any meeting of the Select Committee except when 1 gave evidence before it, so that I did not hear a word of his evidence ; nor have $I$, to the best of my knowledge, read a line of it in the Blue Book. All I know of it is confined to the extracts from it in your article, and to a brief notice of it in some evening newspaper at the 
time. In reading your article, I had not the least suspicion that you rere not referring to the same report as Dr. Tuke had done.

"Messrs Fisher have been betrased into making an unbecoming imputation, which has no other foundation than baseless speculations. "Yours very truly. "H. MAUDSLEY

\section{" 9, Hanover Square,}

"March 24th, 1878."

While adhering to the substance of the remarks I made about Dr. Tuke's evidence, and maintaining them to be fair and honest criticism, I gladly expres our regret that I should have unintentionally mistaken the report, which had been the last report for months before I wrote in November, for that whioh was the last report when Dr. Tuke gave his evidence, and that I should have stated this in my article, though that statement was made in perfert good faith at the time.

But while I most willingly do this, I maintain that a perusal of Dr. Tuke's "last report" ahundantly justifies my criticisms, and does not justify his charges.

There are in England sixteen Registered Hospitals, which contained 2,796 patients at the end of 1875 . Dr. Tuke's wurds in regard to them were :- "The last report of the Commissioners of Lunacy contains records of mismanagement and complaints against these Hospitals." I called this a "grave charge," and I showed that the report of 1876 contained " almost nothing but praise of their condition and management." You do not question that this is the truth. but you say that that report has " nothing to do with the evidence (of Dr. Tuke, given in the preceding April." I must beg leave to differ from you in this very decidedly. I am confident that few persons interested in the work of great charitable institutions will consider that general statements about them of an injurious kind, made in April, 1877, should not be tested by autho. ritative reports about them for 1876 , or that the latter have "nothing to do" with the former. Even if their condition had been as bad as Dr. Tuke describes them in 1875, he should have been glad to hear that they had so decidedly im. proved in 1876

You complain that in quoting the farourable report, which sums up the Commissionerg' general opinion of the Hospitals in 1875, we omitted the " principal exception "mentioned by them, and you then make the astounding admission on the part of your client that his "statement to the Committee "-I presume his sweeping general charge against all the Hospitals of "mismanagemen and complaints "-was based on this one case I had thought the exception insignificant that it simply proved the rule, and therefore did not think it worth while to refer to it. Dr. Tuke, according to your letter, had thought it so important that he told a Committee of the House of Commons engaged in a serious enquiry that its existence condemned sixteen great institutions containing nearly three thousand patients. I am willing to admit at once that controversy between persons who reach such opposite conclusions from the same facts is useless, and I should at once have conoluded this letter had you not-perhaps naturally-attempted to strengthen your client's one case by others you have extracted from the report. Kven Dr. Tuke's all importan exception, when looked at, turns out to be, not one Hospital standing out as badly managed among the sixteen, but one exception in the general good management of one of them in regard to the "class of ordinary attendant there employed on the male side of the Hospital, and with their disregard of the regulations." In your letter you excuse the suicide in Dr. Tuke's Private Asylum on the ground of an attendant's disobedience to orders; what in his own case is made the excuse for an "unfortunate" occurrence appears to become in his mouth before the Committee the ground for an accusation of general mismanagement, not against the Hospital alone in which it occurred, but against the whole. 
You make reference to five occurrences and to one general fact as bearing out Dr. Tuke's imputation. I shall now consider these seriatim.

1. You say that a " death hy violence was consequent upon an attempt to put a patient into a straight waistcoat." You studiously omit to refer to the medical evidence and the finding of the jury that this was a "death from serous apoplexy," adding their opinion that an attendant had used "some short time previously undue violence."

2. You state that a " Registered Horpital physician has treated a patient with acute mania in a farm house, and is cautioned for doing so without certif cates." You do not explain what that has to do with the manazement of the Hospital; it apperrs to us to have no more bearing upon the question of management than Dr. Tuke's treatment of a patient in a private house would have upon the management of his Asylum. That you should refer to such a case appears sinply to show that you have few relevant facts to go on

8. You state that there were three cases of suicide, but you studiously omit to say that in two of them the jury "attriliuted no blame to the officers of the institution; " while in the third case, where no mention is made of the verdict of the jury, the Commissioners state that the accident was due to the carelessness of an attendant-disnissed in consequence-who left the deceased in possession of a hankerchief over night. Were suicides a satisfactory test of management-which, however, I am far from saying they are-I find that during the past ten years the Rexistered Hospitals, with $8,9 \overline{5} 7$ admissions, have had 22, while Dr. Tuke, with 143 admissions at Manor House, has had two, a proportion about six times as great.

4. You state that a patient is reported to have dier uhose life might have heen naved had he been seen by any medical man, and this in "cunsequence of the defective nature of the arrangements and management of the Hospital." You have studiously omitted to quote the latter part of the sentence, which would have shown that this did not refer to any general defective management, but to the single fact that no defihite arrangements had been made to provide for such an emergency as the illness of the Medical Superintendent. The patient went to bed with "what was considered a slight cold," got somewhat worse through the night, though this was not reported to the Medical superintendent till 10.15 a.m. next day. He was too ill himself to see the patient, but sent a once for one of the Cousulting Physicians. "This gentleman was not immediately to be found, and, as events turned out, no medical assistance was obtained till two in the afternoon." "Such remedies as appeured proper were used, and at three p.m.the other Visiting Physician also saw the patient." About this case the Commissioners express the medical theory that "had the patient been seen on the previous evening by any medical man the urgency of the symptoms might have been recognised in time to save his life."

5. You state that "there are many cases of mechanical restraint and seclusion." As regards the latter, I have yet to learn that its judicious use under medical authority is a proof of Asylum mismanagement, and there is not a single complaint that in any of the Hospitals it was used too frequently or unjustifiably in any single case. And as regards mechanical restraint, it secms acarcely credible that a gentleman who has been proved by the Commissionars Reports to resort to its use without surgical reasons in the treatment of his patients should now direct you to refer to its use as a proof of mismanagement in the eight instances whery it was employed in two Hospitals. In the other instances (in four Hospitals) it was used for surgical reasons, where it is held by all authorities in lunacy to be necessary. But the best way to show how the Commissioners mention restraint and seclusion is to quote what they say about them in some of the Hospitals where they were employed.

Barnnood Honse, Gloucester.

"We have examiner the registers, and find no entry of any case of mechanical restraint. As regurds seclusion, it appears to bave been restricted to the females, and to three cases only." 
Linroln Lwnatio Bnspital.

"There was no one restrained or in seclusion : no instance of either is reported since the last visit."

Bethel Hospital, Norrish.

"No person is restrained to-day, except the sufferer from burns, and he is so dealt with for surgical reasons. Seclusion has been used in no instance."

\section{Bethlehrm Hospital.}

"There appears to have been no case of restraint since the last visit, but nine mon and twelve women have been secluded" (out of 250 patients).

York Lunatic Hospitul.

"The only case of instrumental restraint has been that of a man who had his hands tied for eight days for surgical reasons. Seclusion has been very sparingly used."

The Retreat, York.

"The only record of seclusion is in the case of one man for the space of half an hour, and there is none of any mechanicul restraint."

Wonford House, Exeter.

"Two other ladies have been secluded, one on three, the second on two occasions. There is no entry of any resort to mechanical restraint."

6, As regards the care of the gentleman who, in the padded room and alone, gouged out his eyes with his own fingers, the Commissioners do not say that it was a preventible accident, or that any one was to blame; and as regards the general management of the Hospital, instead of finding fault with it, they ctate "the general arrangements for their (the patients') care and treatment seem excellent."

Having by these references to the report to which Dr. Tuke referred shown the real extent and nature of the occurrences alluded to by him and yourselves, the amount of his forberrance when he avoided "sensational and damaging statements, and made no charge whatever," and generously forbore to "damage professional men. for whoin he has high esteem," can be best extimated by the gentlemen whose professional abilities and succers he so graphically described.

I shall now, from the same Blue Book where Dr. Tuke found nothing apparently but uismanagement and complainta, quote statements from the Commissioners' reports on each of the sixteen Hospitals, showing their general oendition or that of their patients :-

Manchester Lunatic Hospital, Cheadle.

"There appears to be very general content and gond order."

Wonford Bouse; Exeter.

"The health of the inmates appears to be very fair." "The dress of the patients of both sexes was not wanting in neatness. The rooms were in good oxdar."

Barnmood House, Gloucester.

"We" "have a very good report to make, both as regarrk the good order and cleanliness of the wards and the condition of the patients."

Liverpool Lmantic. Hospital.

"The personal appearance of the patients in regard to dress and cleanlinese wae fatrly satisfactory." "The wards were throughout in order at the time of our visti:" "The general bealth is good."

\section{Rmpal Albert Asylum, Larioaster.}

"Our visit has antisfied us of the care and kindness the inmates recelved, and of the akill and attention bestowed upon their training and education."

X:T: 
Lincoln Zunatic Hospital.

"Personally, the patients in both divisions were in a satisfactory state." "We had no complaints of the attendants, nor indeed with reference to any other matter."

\section{St. Luke's Hospital.}

"Although every opportunity for complaints was afforded, no patient made any charge of harsh or rough usage."

Bethel Hospital, Norwich.

"Great order and quiet prevailed among the patients during our stay in the hospital. and no single complaint was addressed to us by any inmate of either sex. The general arrangements seem judicious." "The hospital is a real charity, and doubtless supplies a great want."

Northampton Lunatic Asylum.

"No patient appeared to us to have a real grievance, and the general arrangements for their cure and treatment seem excellent."

Nottingham Lunatic Asylum.

"As on former occasions we have an excellent account to give of the condition and treutment of the patients."

Warneford Hospital, near Oxfind.

"We have see them (the patients) all to-day, and have no special remarks to make with refurence to their mental or bodily condition."

Coton Hill Institution, Stafford.

"We can, on the whole, repurt favourably of their (the patients') treatment and condition."

\section{Bethlehem Hospital.}

"We have again pleasure in reporting that the Hospital is in excellent order, and its state very creditable to those enguged in its management."

Eurlennod Idiot Asylum.

"It is with much pleasure that we are agrin able to record our opinion of the satisfactory atate of the Asylum, and of the zeal and ability that mark its management and superintendence."

York Lunatic Hospital.

"We have inspected this Hospital, and seen all the patients to-day. They were, on the whole, in a satisfactory state."

The Retreat, York.

"We have seen (the patients) all, and found them quiet and orderly. Some few requests were made to us for discharge, but no complaint respecting the treatmeut received."

As if those favourable opinions of the Commissioners in regard to each Hospital separately might not be held sufficient to stainp them emphutically enough with their approval, they say, "We have so high an opinion of such institutions as this, that we again take leave to press upon the consideration of the Committee (of the Nottingham Hospital) the question of the extension of the present accommodation."

A perusal of this evidence, which I hold to be absolutely conclusive as to the general good condition and management of these excellent establishments, shows to any mind free from prejudice and capable of extimating the facts, on what small matters Dr. Tuke built his grave and general charges, and how likely to be misleading and prejudicial his statements are.

The facts which you mention as the results of your inquiries into Dr Tuke's re. lations to the late Dr. Conolly may be of interest to his friends, though some of 
them are new to me, but I fail to see what relevancy they have to the subject of your letter, much less how they can be held to justify or excuse in any way a mode of treatment which Dr. Conolly would have earnestly and indignantly repudiated. He said, "No fallacy can be greater than that of imagining what is called a moderate use of mechanical restraint to be consister $t$ with a general plan of treatment in all other respects complete, unobjectionable, and humane. The abolition must be absolwte, or it cannot be efficient." "In a well-regulated Asylum, such mudes of restraint are never thought excusable." "Restruint and neglect may be considered as sy'nonynous." "There is no Asylum in the world in which all mechanical restraints may not be abolished, not only with perfect safety, but with incalculable advant"ge."

I am gratified that you do not reiterate nor affect to support Dr. Tuke s statements about the medical men connected with the Registered Hospitals having no repute for treatment or having never come to the front, but $I$ think it would have been a nore handsome proceeding had he withdrawn them.

I do not for a moment admit your interpretation of the spirit and motive of my criticisms, which were made not for the purpose of injuring Dr. Tuke, but in the discharge of a public duty as the Editor of a Medical Journal in defence of valualle Medical and Philanthropic public institutions, whi h I considered had been undeservedly stigmatized, and about whose Medical Officers statements had beell made most offensive to them. I must also enter my protest against the theory that the proprietor of a Private Asylum who has made charges againgt public Hospitals and their Physicians should, when his charges are met by fair and honest comparison, founded on public reports, recklessly iinpute barl motives.

You will probably agree that there is not mu ih use in prolonging this corres. pondence, but should you deem proper to do so, you will please to commuuicate through my agent, Mr. John A. Truill, W.S., 88, George street, Edinburgh.

I propose to publish, along with the former correspondence, your letter and this reply.

I am, Gentlemen, Your obedient servant

T. 8. CLOUSTON.

INTERNATIONAL PSYCHOLOGICAL CONGRESS IN PARIS, ON THE БTH OF AUGUST, 1878.

MEDICO.PSYCHOLOGICAL SOCIETY OF PARIS.

Paris, 1st June, 1878.

Resolutions and Programme of the International Psychological Congress.

The Committee of Organisation, composed of Drs. Baillarger (President), Blanche, Dumesnil, J. Falret, Lasegue, Lunier, Legrand du Saulle, Motet, Ritti, have framed the following resolutions and programme :-

Kesolutiun 1. - That an International Congress on Mental Medicine win be opened at Paris on August 5th, 1878, under the auspices of the Medico-Puychological -ociety.

Resolution II.-That the Congress, which will be of an exclusively scientific character, will extend over eight days.

Resolutiou 1II.-That the Congress will be composed of the original and ordinary national and foreign members.

Originul members are the titled and honorary members of the Medico-Paychological Society, whose subscription is 25 francs.

Ordinary members are the Me.lical Men, the Directors of Foreign and National Asylums, all persons interested in mental diseases, who have sent their subsoription to the General Socretary of the Medico-Psychological Society (Dr. Motet, 161, Rue de Charonne, Paris).

Subscription 10 francs. 